\title{
Impact of the COVID-19 pandemic on interventional cardiology practice: results of the EAPCI survey
}

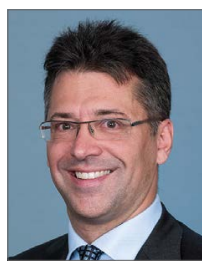

Marco Roffi ${ }^{1 *}, \mathrm{MD}$; Davide Capodanno², MD, PhD; Stephan Windecker ${ }^{3}, \mathrm{MD}$; Andreas Baumbach ${ }^{4,5}, \mathrm{MD}, \mathrm{PhD}$; Dariusz Dudek ${ }^{6,7}, \mathrm{MD}, \mathrm{PhD}$

1. Division of Cardiology, University Hospitals, Geneva, Switzerland; 2. Division of Cardiology, CAST, P.O. "G. Rodolico", Azienda Ospedaliero-Universitaria "Policlinico-Vittorio Emanuele", University of Catania, Catania, Italy; 3. Department of Cardiology, Swiss Cardiovascular Center, University Hospital Bern, Bern, Switzerland; 4. Centre for Cardiovascular Medicine and Devices, William Harvey Research Institute, Queen Mary University of London, Barts Heart Centre, London, United Kingdom; 5. Yale University School of Medicine, New Haven, CT, USA; 6. Institute of Cardiology, Jagiellonian University Medical College, Krakow, Poland; 7. Maria Cecilia Hospital GVM, Cotignola, Ravenna, Italy

GUEST EDITOR: Franz-Josef Neumann, MD; University Heart Centre Freiburg Bad Krozingen, Germany

This paper also includes supplementary data published online at: https://eurointervention.pcronline.com/doi/10.4244/EIJ-D-20-00528

\section{Introduction}

COVID-19 disease, caused by the severe acute respiratory syndrome coronavirus 2 (SARS CoV-2), has imposed an unprecedented burden on healthcare systems worldwide. While guidance on management of cardiovascular conditions in the setting of COVID-19 is being gathered, little is known about the effects of the pandemic on interventional cardiology practice ${ }^{1}$. The first reports originating from highly affected areas describe a reduction in the number of patients presenting to the emergency department (ED) with acute coronary syndromes (ACS) $)^{2,3}$. In order to shed light on the impact of the COVID-19 pandemic on the management of patients encountered in routine interventional cardiology practice, the European Association of Percutaneous Coronary Interventions (EAPCI) of the European Society of Cardiology conducted a survey among its members.

\section{Methods}

From 1 April to 15 April 2020, a link to a web-based survey including 83 questions was mailed to EAPCI members, with one reminder. In addition, the survey was accessible on the web at https://www.pcronline.com/ and https://www.pcronline.com/ Cases-resources-images/Zoom-on/COVID-19/EAPCI-COVIDSURVEY. A total of 636 members responded - 49\% from Western Europe, $21 \%$ from Eastern Europe, $13 \%$ from Africa/Middle East, $11 \%$ from Australasia and $6 \%$ from the Americas. Unless stated otherwise, percentages in the text, Figures and Tables refer to the proportion of respondents giving an answer/affirming a statement.

\section{Results}

\section{COVID-19 STATUS AND TESTING POLICIES}

The majority of the respondents were employed in COVID-19designated hospitals (58\%), while $31 \%$ were from non-COVID-19 hospitals; for the remaining, the COVID-19 status of the hospital was not defined/unknown. With respect to the COVID-19 institutional testing policy, $12 \%$ tested all patients independently of symptoms, $67 \%$ tested all patients with symptoms suspicious of COVID-19 and the remaining were not able to test all suspected patients because of lack of kits.

\section{IMPACT ON CATH LAB PERSONNEL AVAILABILITY}

Cardiac catheterisation laboratory (cath lab) personnel availability, for both physicians and paramedics, was affected by the pandemic. The proportion of respondents stating that at least one cath lab physician was in quarantine, infected with COVID-19, or dispatched to other departments in need such as ED or intensive care units (ICU), was $59 \%, 43 \%$, and $59 \%$, respectively. The corresponding proportions for cath lab nurses and technicians were $52 \%$, $36 \%$ and $59 \%$. Details on the impact of the COVID-19 pandemic on cath lab personnel availability are reported in Supplementary Figure 1 and Supplementary Figure 2.

*Corresponding author: Geneva University Hospital, Rue Gabrielle Perret-Gentil 4, 1211 Geneva 14, Switzerland.

E-mail:marco.roffi@hcuge.ch 


\section{IMPACT OF COVID-19 PANDEMIC ON CATH LAB ACTIVITY}

The reduction in cath lab activity has been considerable, particularly for elective procedures. Figure 1 shows the degree of reduction in activity for the individual procedures. In ACS, coronary angiography and percutaneous coronary intervention (PCI) have been reduced by various extents according to clinical presentation, with the greatest reduction in activity observed in patients presenting with unstable angina. Of note, $27 \%$ and $31 \%$ of the respondents stated that the activity was reduced also in patients with ST-elevation myocardial infarction (STEMI) and cardiac arrest, respectively. Other observations related to ACS management are reported in Table 1, including a reduction in hospitalisations/referrals, an increase in delays to coronary angiography/PCI, the choice of fibrinolysis instead of primary PCI in STEMI, a reduction in cardiac rhythm monitoring time, a restriction in the indications for ICU, and an increase in presentation with cardiogenic shock or mechanical complications.

With respect to elective procedures, only $5 \%$ of the respondents stated that diagnostic angiography or left/right heart catheterisation was not affected, while among those affected a complete discontinuation of these activities was reported in 51\%. PCI in the setting of chronic coronary syndromes was unaffected in $9 \%$, while among those who reduced the activity a complete stop was reported in $50 \%$. Structural heart intervention programmes were also profoundly affected. Only $11 \%$ of the respondents stated that TAVI programmes ran unchanged, while among those affected a complete discontinuation of the procedure was reported in $51 \%$. The corresponding proportions for transcatheter mitral valve repair were $12 \%$ and $73 \%$. Other structural heart interventions, such as closure of patent foramen ovale, atrial septal defect, or left atrial appendage as well as alcohol septal ablation were not affected in
Table 1. Impact of the COVID-19 pandemic on the management of patients with acute coronary syndromes.

\begin{tabular}{|c|c|}
\hline \multirow[t]{6}{*}{ STEMI } & Coronary angiography and $\mathrm{PCI}$ reduced/stopped (27\%) \\
\hline & $\begin{array}{l}\text { Increased delay in reperfusion related to COVID-19 } \\
(48 \%)\end{array}$ \\
\hline & $\begin{array}{l}\text { Fibrinolysis administered because of logistical reasons } \\
\text { related to the COVID-19 pandemic }(22 \%)\end{array}$ \\
\hline & $\begin{array}{l}\text { Increase in cardiogenic shock/mechanical complication } \\
(28 \%)\end{array}$ \\
\hline & Restriction in the indication for intensive care (39\%) \\
\hline & Reduction in cardiac rhythm monitoring time (19\%) \\
\hline \multirow[t]{3}{*}{ NSTEMI } & Coronary angiography and $\mathrm{PCI}$ reduced/stopped (38\%) \\
\hline & Increased delay to early invasive strategy (57\%) \\
\hline & Reduction in cardiac rhythm monitoring time (25\%) \\
\hline All ACS & Reduction in hospitalisations/referrals (89\%) \\
\hline \multicolumn{2}{|c|}{$\begin{array}{l}\text { Percentages refer to the proportion of survey participants supporting the } \\
\text { statement. ACS: acute coronary syndromes; NSTEMI: non-ST-elevation } \\
\text { myocardial infarction; PCI: percutaneous coronary intervention; } \\
\text { STEMI: ST-elevation myocardial infarction }\end{array}$} \\
\hline
\end{tabular}

$9 \%$, while among the programmes affected a complete discontinuation of activities was reported in 79\%. Among centres that discontinued a specific procedure, the process was abrupt, faster for elective than for urgent interventions, and in all centres completed within roughly three weeks (Supplementary Figure 3).

\section{GENERAL PROTECTIVE MEASURES IN THE CATH LAB}

In patients requiring non-emergent cath lab procedures (e.g., nonST-elevation myocardial infarction [NSTEMI] with no recurrent ischaemia), testing of all patients with symptoms suspicious of
Has the procedure been reduced or stopped?

ICA/PCI for STEM

ICA/PCI for NSTEM

$\mathrm{ICA} / \mathrm{PCI}$ for UA

ICA/PCI for cardiac arrest

ICA/PCI for CCS

Elective diagnostic catheterisation

Transcatheter mitral valve repair

Other structural interventions

\begin{tabular}{|c|c|c|}
\hline & $73 \%$ & $27 \%$ \\
\hline & $62 \%$ & $38 \%$ \\
\hline & $57 \%$ & $43 \%$ \\
\hline & $69 \%$ & $31 \%$ \\
\hline $9 \%$ & & \\
\hline $5 \%$ & & \\
\hline $11 \%$ & & \\
\hline $12 \%$ & & \\
\hline $9 \%$ & & \\
\hline
\end{tabular}

If the procedure has been reduced or stopped, can you estimate by how much?

\begin{tabular}{|c|c|c|c|}
\hline $27 \%$ & $35 \%$ & $28 \%$ & $10 \%$ \\
\hline $22 \%$ & $36 \%$ & $33 \%$ & $9 \%$ \\
\hline $14 \%$ & $33 \%$ & $39 \%$ & $14 \%$ \\
\hline $17 \%$ & $30 \%$ & $30 \%$ & $23 \%$ \\
\hline $5 \% \quad 12 \%$ & $32 \%$ & $50 \%$ & \\
\hline $5 \% \quad 11 \%$ & $33 \%$ & $51 \%$ & \\
\hline $7 \% \quad 11 \%$ & $31 \%$ & $51 \%$ & \\
\hline $5 \% 5 \% \quad 17 \%$ & & $73 \%$ & \\
\hline$\% 5 \% \quad 13 \%$ & & $79 \%$ & \\
\hline $\begin{array}{l}\text { Reduced b } \\
\text { Reduced b }\end{array}$ & $\begin{array}{l}5 \% \\
5 \%\end{array}$ & $\begin{array}{l}\text { ced by } 50 \% \\
\text { ed }\end{array}$ & \\
\hline
\end{tabular}

Figure 1. Impact of the COVID-19 pandemic on cath lab activity. Elective diagnostic catheterisation included diagnostic coronary angiography and leftright heart catheterisations. Percentages refer to the proportion of survey participants stating the degree of reduction of each individual procedure. Other structural heart interventions included closure of patent foramen ovale, atrial septal defect, or left atrial appendage as well as alcohol septal ablation. CCS: chronic coronary syndrome; ICA: invasive coronary angiography; NSTEMI: non-STelevation myocardial infarction; PCI: percutaneous coronary intervention; STEMI: ST-elevation myocardial infarction; UA: unstable angina 
COVID-19 was performed in 55\%, while testing of all patients irrespective of symptoms was possible in $18 \%$; in $25 \%$ of the cases it was not possible to test all patients with symptoms suspicious of COVID-19 owing to the lack of testing kits, while the remaining respondents were not sure. In order to reduce the risk of contagion for the cath lab personnel and contamination of the room and equipment, some procedures usually performed in the cath lab were performed elsewhere (e.g., ED, ICU) in patients with symptoms suspicious of COVID-19. This was the case for pericardiocentesis for $23 \%$ of the respondents, while the corresponding proportions for intra-aortic balloon pump placement and right heart catheterisation were $13 \%$ and $11 \%$.

With respect to the triage of patients, $92 \%$ of the respondents stated that patients were surveyed regarding potential exposure or symptoms suspicious of COVID-19 before granting access to the cath lab. Eighty-one percent of the respondents mandated body temperature measurement and $86 \%$ the wearing of a surgical mask in all patients before entering the cath lab. Forty-three percent of the respondents affirmed having a dedicated cath lab room for patients with symptoms suspicious of COVID-19 or COVID-19 positive. A widening of the indication for intubation in the ED/ICU in patients scheduled for an invasive procedure with borderline respiratory failure and/or haemodynamic instability and/or vomiting in order to avoid emergent intubation in the cath lab was implemented by $54 \%$ of the respondents.

\section{PERSONAL PROTECTION IN THE CATH LAB}

The results of the survey on dedicated personal protective equipment (PPE) for the primary operator performing a procedure on patients with symptoms suspicious of COVID-19 or COVID-19 positive are listed in Figure 2. The main reason for not using PPE was its unavailability. Particularly concerning was the observation that $19 \%$ of the respondents were not using FFP2/FFP3 face masks while treating patients with symptoms suspicious of COVID-19 or COVID-19 positive at risk for aerosol generation (e.g., in patients with borderline respiratory failure at risk for intubation and/or haemodynamic instability and/or vomiting). Powered air purifying respirators (PAPR) were available for $28 \%$ of the operators. The results of the survey with respect to dedicated PPE for circulating cath lab personnel are available in Supplementary Figure 4-Supplementary Figure 7. A specific protocol for wearing and removing PPE was implemented in $91 \%$ of responders. Sixty-eight percent of the respondents affirmed that a specific cath lab cleaning protocol was in place after the treatment of a patient with symptoms suspicious of COVID-19 or COVID-19 positive, while $20 \%$ stated that they used a "standard" cleaning protocol, as for other infections, and the remainder did not know.

\section{Discussion}

The main findings of the survey, involving over six hundred interventional cardiologists mainly from Europe, that we conducted from 1 April to 15 April 2020 are summarised in Table 2. At times, the pandemic overwhelmed health systems. This is shown by the fact that overall it was not possible to test COVID-19 suspected patients systematically and that the availability of recommended PPE for operators and cath lab personnel was suboptimal and not according to proposed standards ${ }^{4}$. Particularly worrisome was the observation that one out of five respondents was not using an FFP2/FFP3 face mask while treating patients with symptoms

\section{Table 2. Key findings of the EAPCI COVID-19 survey.}

Kits not available in all hospitals to test all COVID-19 suspected patients.

Cath lab personnel (both doctors and paramedics) availability affected (quarantine, contagion, need of other departments).

Massive and abrupt reduction in elective activity, both coronary and structural

Management of acute coronary syndromes affected (Table 1).

In the cath lab body temperature measurement and surgical mask for the patients are very common.

Availability of personal protective equipment in cath labs suboptimal.

\begin{tabular}{|c|c|c|c|c|}
\hline \multirow[b]{2}{*}{ FFP2/FFP3 for standard patients } & \multicolumn{2}{|c|}{$\begin{array}{l}\text { Do you use this personal } \\
\text { protective equipment? }\end{array}$} & \multicolumn{2}{|c|}{$\begin{array}{l}\text { If you don't use this personal protective equipment, } \\
\text { can you tell why? }\end{array}$} \\
\hline & $78 \%$ & $22 \%$ & $76 \%$ & $24 \%$ \\
\hline $\begin{array}{r}\text { FFP2/FFP3 mask for patients at risk } \\
\text { for aerosol generation }\end{array}$ & $81 \%$ & $19 \%$ & $80 \%$ & $20 \%$ \\
\hline Double gloves & $72 \%$ & $28 \%$ & $79 \%$ & $21 \%$ \\
\hline Dedicated eye protection & $79 \%$ & $21 \%$ & $79 \%$ & $21 \%$ \\
\hline Dedicated face shield & $68 \%$ & $32 \%$ & $76 \%$ & $24 \%$ \\
\hline Extra gown & $51 \%$ & $3 \%$ & $59 \%$ & $41 \%$ \\
\hline Dedicated shoe protection & $60 \%$ & $40 \%$ & $56 \%$ & $44 \%$ \\
\hline
\end{tabular}

Figure 2. Use of personal protective equipment (PPE) by the primary operator treating patients with symptoms suspicious of COVID-19 or COVID-19 positive in the cath lab. Percentages refer to the proportion of survey participants supporting the statement. 
suspicious of COVID-19 or COVID-19 positive at risk for aerosol generation. The pandemic also affected cath lab personnel availability, both doctors and paramedics, due to quarantine measures, direct contagion, or personnel being dispatched to other departments of the hospital in need, such as ED and ICU. The impact of the pandemic on elective cath lab activity was massive for both coronary and structural heart interventions. Within roughly three weeks, all centres that discontinued a specific interventional activity had halted their programmes.

In accordance with first reports from highly affected areas, the vast majority of respondents observed a reduction in hospitalisations/referrals for $\mathrm{ACS}^{2,3}$. A reduction in or discontinuation of primary PCI for STEMI was reported by approximately one quarter of the respondents. Additional findings on ACS management included an increase in the delays to coronary angiography/ PCI, the choice of fibrinolysis instead of primary PCI in STEMI, a reduction in cardiac rhythm monitoring time, a restriction in the indications for ICU, and an increase in the prevalence of cardiogenic shock and mechanical complications.

\section{Limitations}

As the evolution of the epidemic was extremely rapid, these findings apply only for the period of time investigated. As the cath lab name was not tracked in the survey, we cannot exclude that more than one interventionalist of the same institution participated.

\section{Conclusion}

The survey suggests that interventional cardiology practice has been disrupted in multiple aspects by the COVID-19 pandemic, ranging from cath lab personnel availability, to the need for personal protection, to the management of ACS patients and the massive reduction in procedural activity.

\section{Impact on daily practice}

The COVID-19 pandemic has deeply affected interventional cardiology practice.

\section{Guest Editor}

This paper was guest edited by Franz-Josef Neumann, MD; University Heart Centre Freiburg Bad Krozingen, Germany.

\section{Acknowledgements}

We thank Marielle de la Torre, Francois Serrano and the entire EAPCI/ESC team at the European Heart House for helping to conduct the survey and the PCR leadership for the opportunity to access the survey from their website.

\section{Conflict of interest statement}

M. Roffi reports institutional research grants from Biotronik, GE Healthcare, Medtronic and Boston Scientific, outside the submitted work. S. Windecker reports grants from Abbott, Amgen, BMS, Bayer, Boston Scientific, Biotronik, Cardinal Health, CSL Behring, Daiichi Sankyo, Edwards Lifesciences, Johnson \& Johnson, Medtronic, Quebert, Polares, Sanofi and Terumo, outside the submitted work. A. Baumbach has received institutional research support from Abbott Vascular and honoraria from AstraZeneca, Sinomed, MicroPort, Abbott Vascular, Cardinal Health and KSH. The other authors have no conflicts of interest to declare. The Guest Editor has no conflicts of interest to declare.

\section{References}

1. https://www.escardio.org/Education/COVID-19-and-Cardiology/ESCCOVID-19-Guidance. Last accessed 5 May, 2020.

2. Garcia S, Albaghdadi MS, Meraj PM, Schmidt C, Garberich R, Jaffer FA, Dixon S, Rade JJ, Tannenbaum M, Chambers J, Huang PP, Henry TD. Reduction in ST-Segment Elevation Cardiac Catheterization Laboratory Activations in the United States during COVID-19 Pandemic. $J$ Am Coll Cardiol. 2020;75:2871-2.

3. De Filippo O, D'Ascenzo F, Angelini F, Bocchino PP, Conrotto F, Saglietto A, Secco GG, Campo G, Gallone G, Verardi R, Gaido L, Iannaccone M, Galvani M, Ugo F, Barbero U, Infantino V, Olivotti L, Mennuni M, Gili S, Infusino F, Vercellino M, Zucchetti O, Casella G, Giammaria M, Boccuzzi G, Tolomeo P, Doronzo B, Senatore G, Marra WG, Rognoni A, Trabattoni D, Franchin L, Borin A, Bruno F, Galluzzo A, Gambino A, Nicolino A, Truffa Giachet A, Sardella G, Fedele F, Monticone S, Montefusco A, Omedè P, Pennone M, Patti G, Mancone M, De Ferrari GM. Reduced Rate of Hospital Admissions for ACS During Covid-19 Outbreak in Northern Italy. N Engl J Med. 2020 Apr 28. [Epub ahead of print].

4. Chieffo A, Stefanini GG, Price S, Barbato E, Tarantini G, Karam N, Moreno R, Buchanan GL, Gilard M, Halvorsen S, Huber K, James S, Neumann FJ, Möllmann J, Roffi M, Tavazzi G, Mauri i Ferré J, Windecker S, Dudek D, Baumbach A. EAPCI Position Statement On Invasive Management Of Acute Coronary Syndromes During The Covid-19 Pandemic. EuroIntervention. 2020;16: $233-46$.

\section{Supplementary data}

Supplementary Figure 1. Unavailability of cath lab medical staff due to the COVID-19 pandemic.

Supplementary Figure 2. Unavailability of cath lab nurses and technicians due to the COVID-19 pandemic.

Supplementary Figure 3. Discontinuation of activities.

Supplementary Figure 4. Use of face masks by the circulating personnel in the cath lab.

Supplementary Figure 5. Use of dedicated eye protection by the circulating personnel in the cath lab.

Supplementary Figure 6 . Use of face shields by the circulating personnel in the cath lab.

Supplementary Figure 7. Use of double gloves, an extra gown for biological protection and extra shoe protection by the circulating personnel in the cath lab.

The supplementary data are published online at:

https://eurointervention.pcronline.com/

doi/10.4244/EIJ-D-20-00528 


\section{Supplementary data}

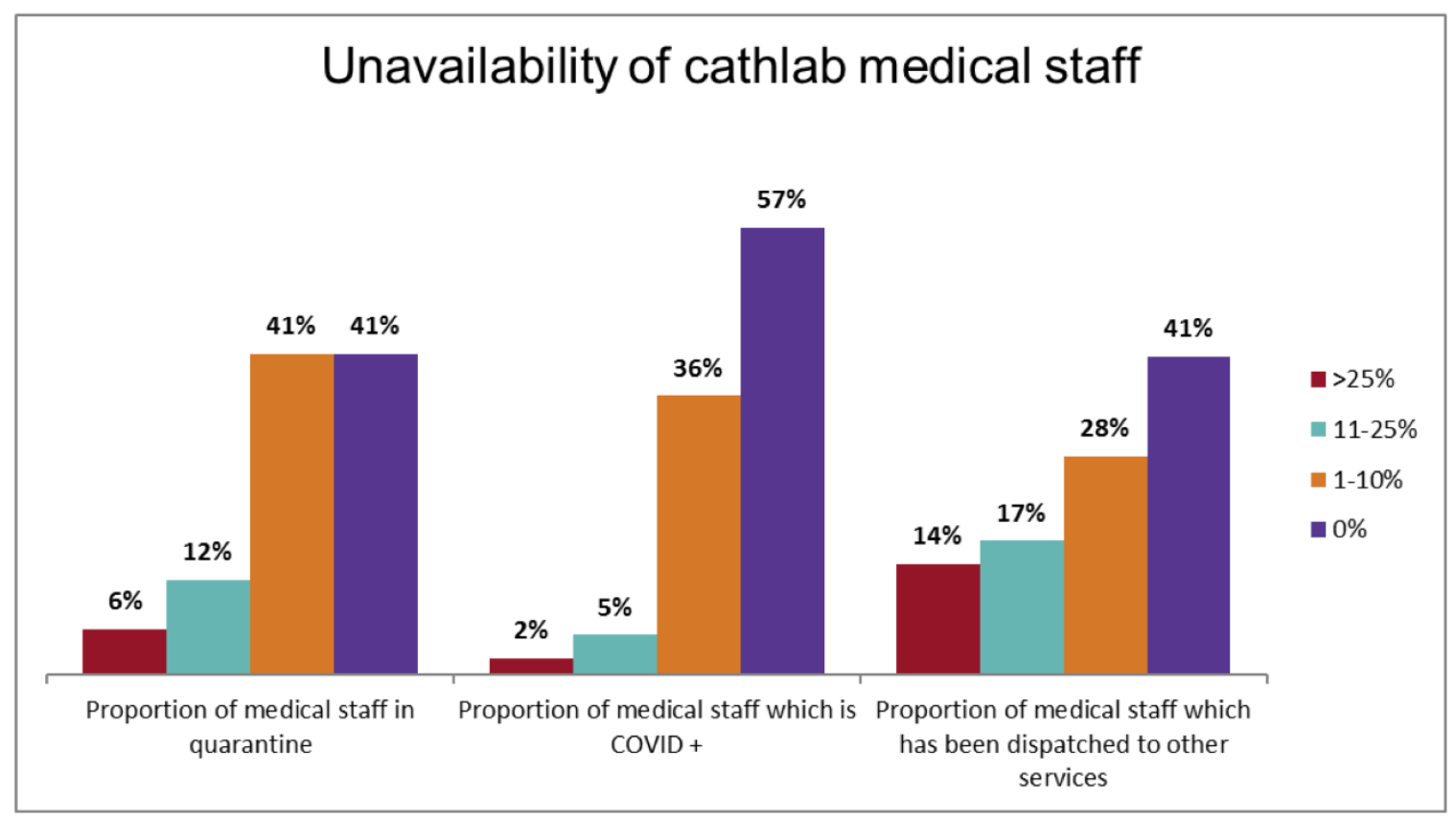

Supplementary Figure 1. Unavailability of cath lab medical staff due to the COVID-19 pandemic.

Percentages in the key refer to the proportion of survey participants stating that a certain proportion of the team was not available. 


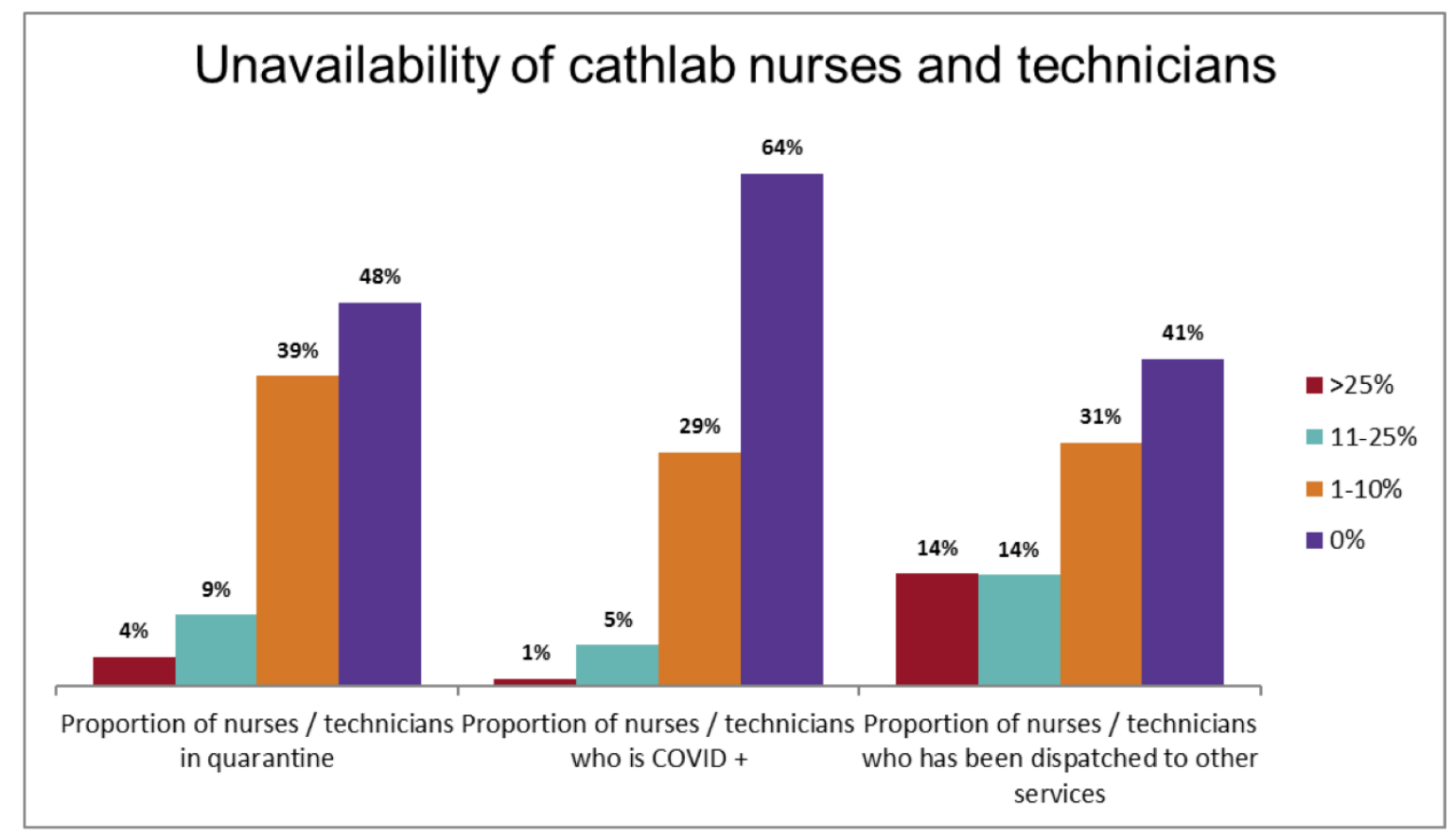

Supplementary Figure 2. Unavailability of cath lab nurses and technicians due to the COVID-19 pandemic.

Percentages in the key refer to the proportion of survey participants stating that a certain proportion of the team was not available. 


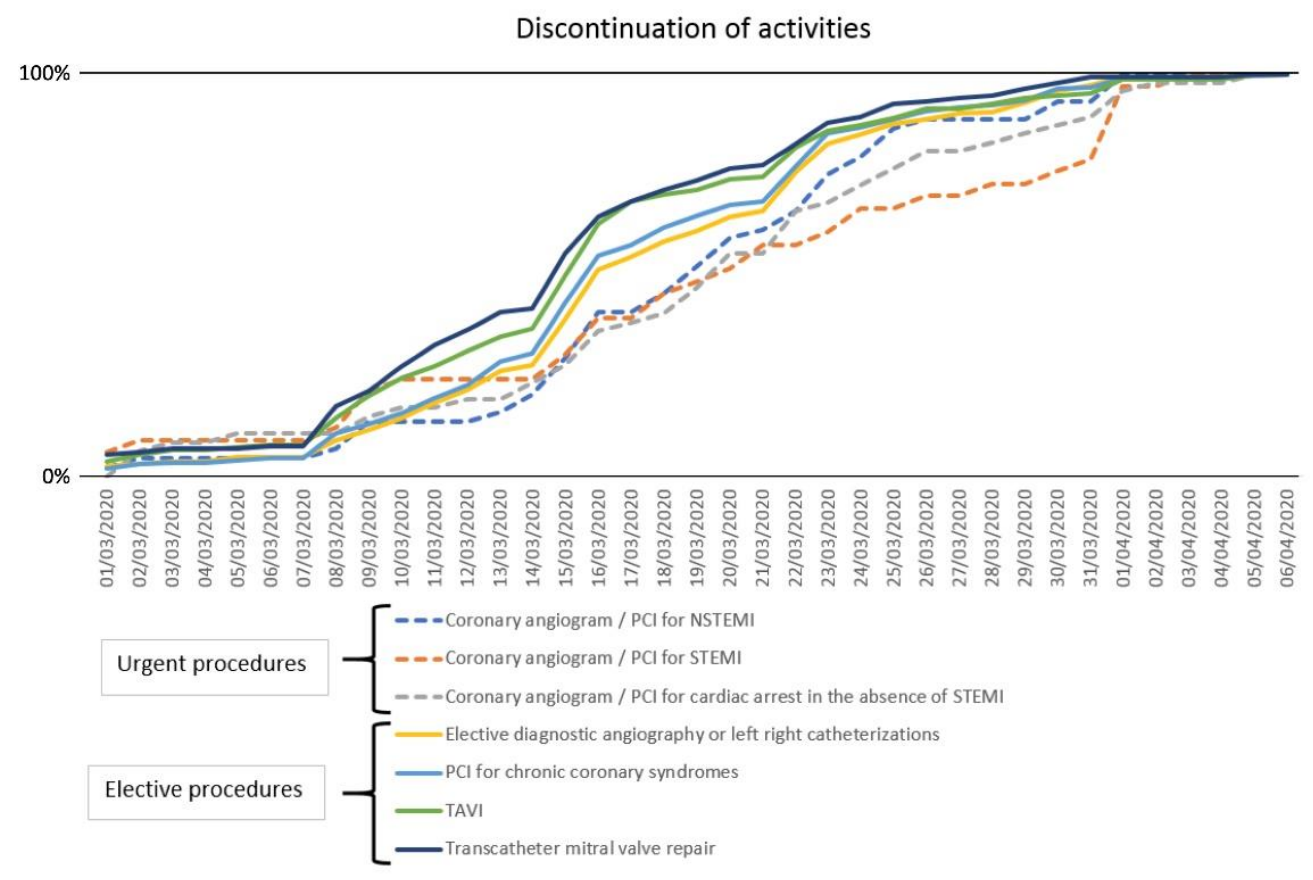

Supplementary Figure 3. Discontinuation of activities.

Among the centres which discontinued a specific intervention, the temporal evolution of the process is shown. This took roughly three weeks (from 7 March to 1 April 2020) and was faster for elective procedures.

NSTEMI: non-ST-elevation myocardial infarction; PCI: percutaneous coronary intervention; STEMI: ST-elevation myocardial infarction; TAVI: transcatheter aortic valve implantation 


\section{Type of mask used by circulating personnel}

$59 \%$

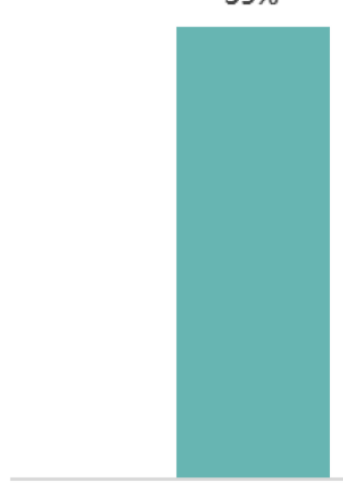

$28 \%$

$13 \%$

Dedicated masks (FFP2/FFP3) for all COVID suspect/confirmed patients

Dedicated masks (FFP2/FFP3) only for COVID suspect/confirmed patients at risk of aerosol generation (emergent intubation/CPR/suctioning)

Supplementary Figure 4. Use of face masks by the circulating personnel in the cath lab.

Percentages refer to the proportion of survey participants supporting the statement. 


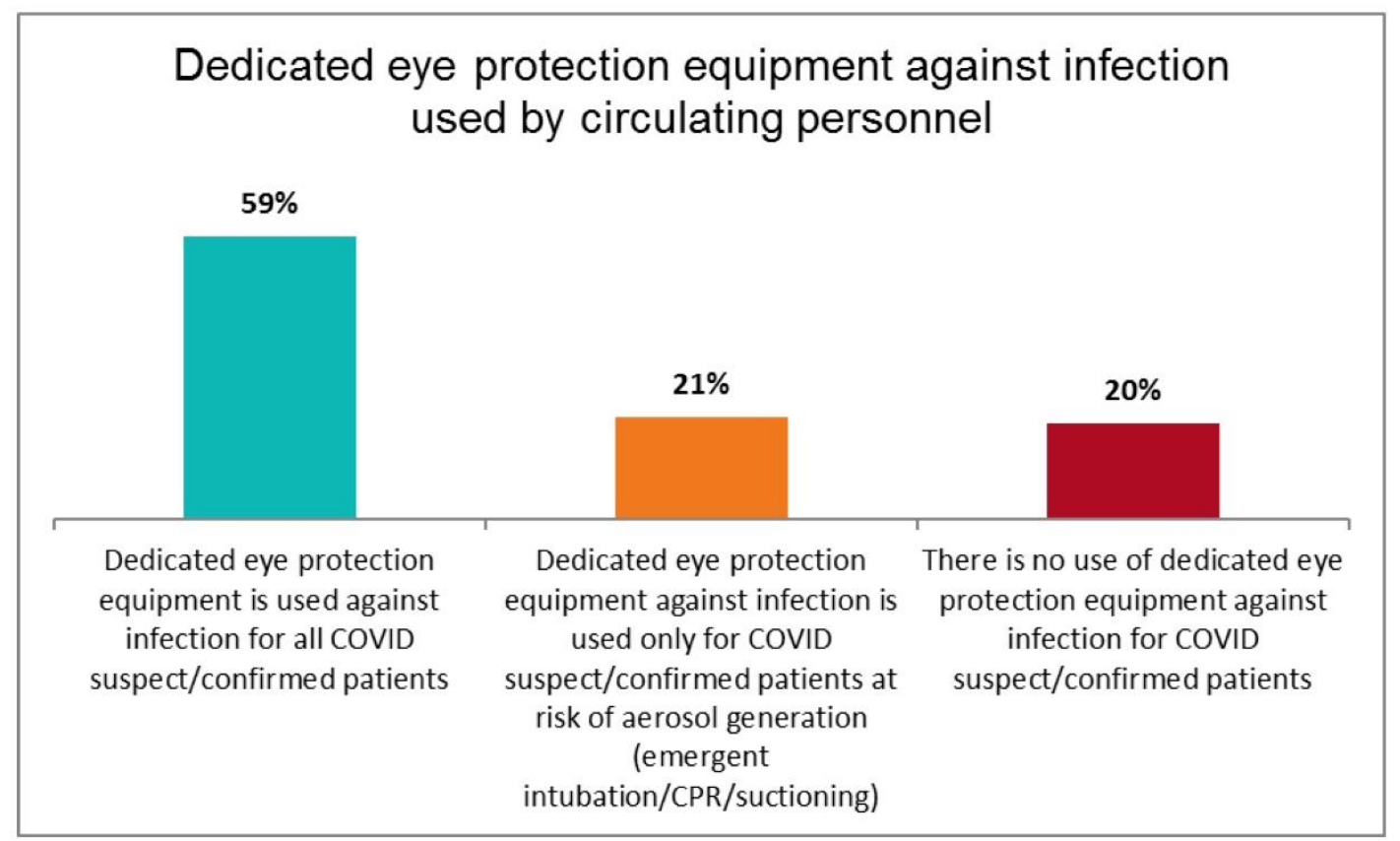

Supplementary Figure 5. Use of dedicated eye protection by the circulating personnel in the cath lab.

Percentages refer to the proportion of survey participants supporting the statement. 


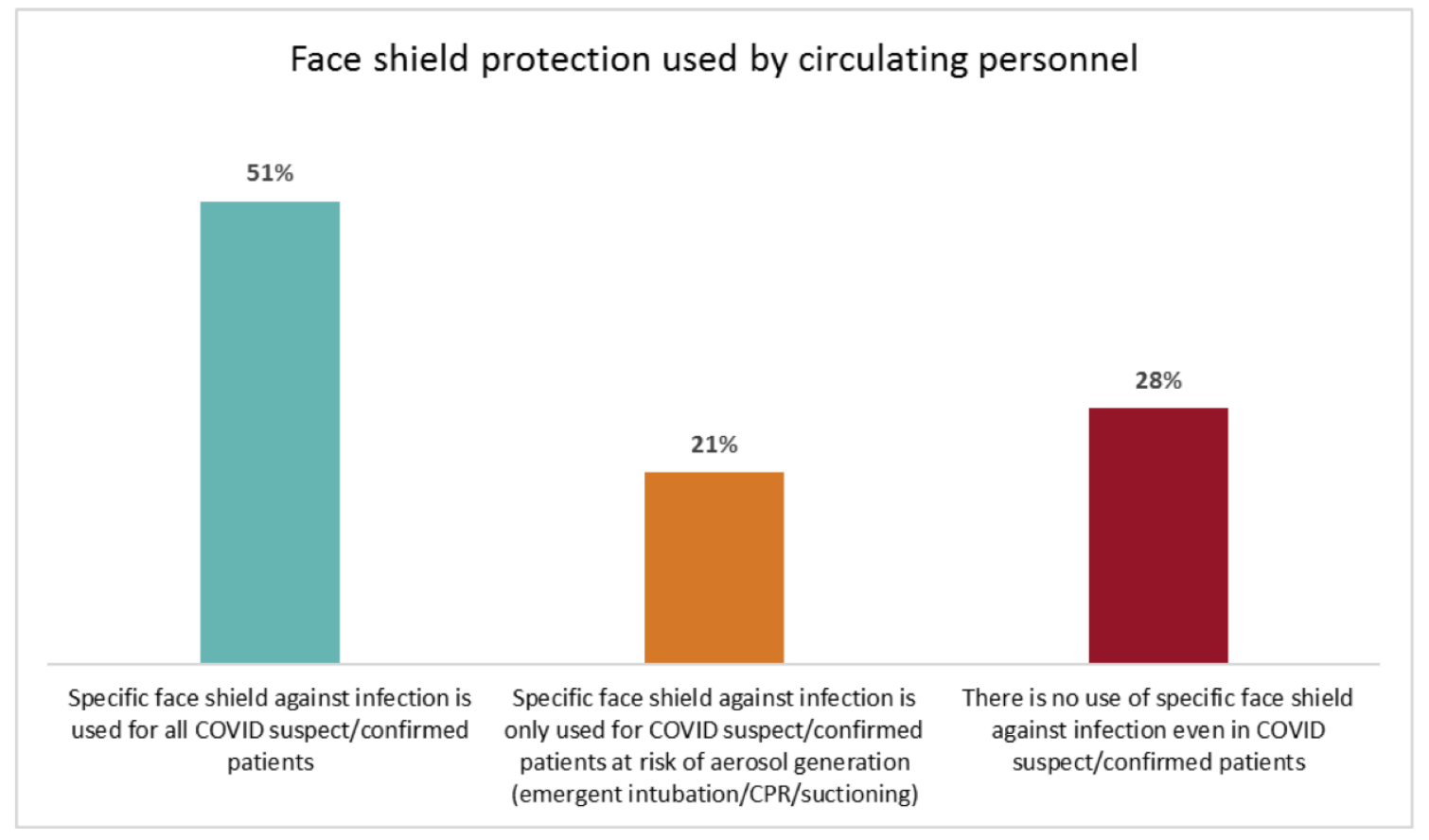

Supplementary Figure 6. Use of face shields by the circulating personnel in the cath lab.

Percentages refer to the proportion of survey participants supporting the statement. 


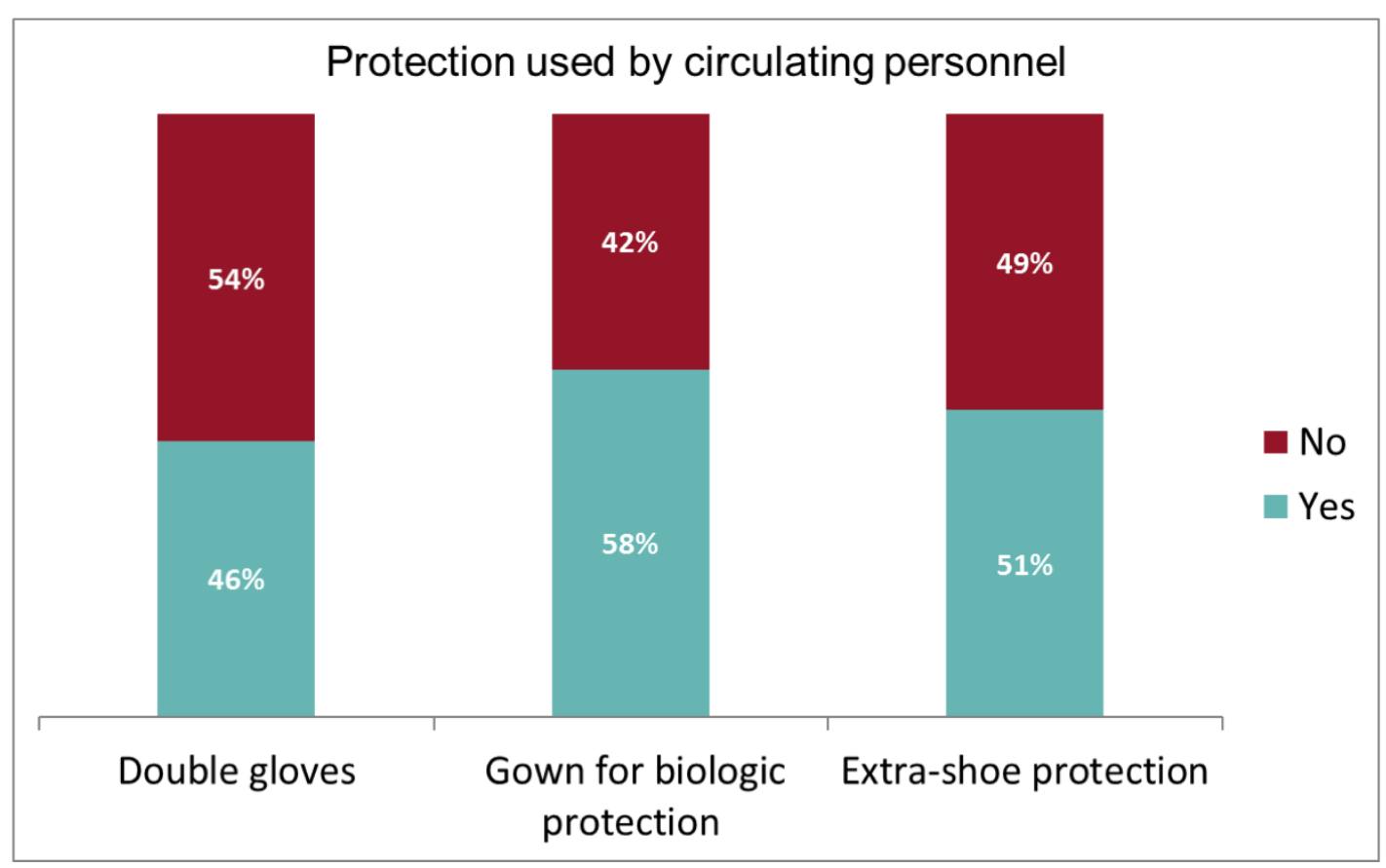

Supplementary Figure 7. Use of double gloves, an extra gown for biological protection and extra shoe protection by the circulating personnel in the cath lab.

Percentages refer to the proportion of survey participants supporting the statement. 